\title{
The role of the electronic structure and solvent in the dye- sensitized solar cells based on Zn-porphyrins; Theoretical study
}

\author{
Foroogh Arkan ${ }^{\mathrm{a}}$, Mohammad Izadyar ${ }^{*}$, Ali Nakhaeipour ${ }^{\mathrm{b}}$ \\ ${ }^{a}$ Department of Chemistry, International Campus of Ferdowsi University of Mashhad, Mashhad, Iran \\ ${ }^{b}$ Department of Chemistry, Faculty of Sciences, Ferdowsi University of Mashhad, Mashhad, Iran \\ Telefax: ++985138795457 \\ izadyar@um.ac.ir
}

\begin{abstract}
In this work, using the density functional theory (DFT) and time-dependent DFT (TDDFT), we have theoretically studied the electronic structures, quantum reactivity parameters and absorption spectra of the several dyes based on Zn-porphyrin derivatives in the gas phases, methanol $(\mathrm{MeOH})$ and tert-buthanol $(\mathrm{t}-\mathrm{BuOH})$. Also, open-circuit photovoltage $\left(V_{O C}\right)$, exciton binding energy $(E B E)$, light harvesting efficiency $(L H E)$, the free energy change of regeneration $\left(\Delta G_{\text {regen.(dye) }}\right)$, and the free energy change of electron injection $\left(\Delta G_{\text {inject }}\right)$ have been investigated. The studied dyes in the presence of the solvents showed a smaller gap of the highest occupied molecular orbital (HOMO) - the lowest unoccupied molecular orbital (LUMO) and lower EBE, a higher intensity and oscillator strength and red shift in the absorption spectra. These changes facilitate the charge transfer (CT) phenomena in the nano-structures of the dyes and improve the solar cell efficiency. Chemical modifications of the dyes by electron donor groups or conjugated system extension, improve the incident photon to current conversion efficiency (IPCE), the energy gap between the LUMO of the dye and the conduction band (CB) of the $\mathrm{TiO}_{2}\left(e V_{O C}\right)$, and the $L H E$ of these dye-sensitized solar cells (DSSCs). Finally, some correlations between the molecular descriptors and solar cell parameters were analyzed.
\end{abstract}


Keywords: solar cell, sensitizer, absorption spectra, binding energy, photovoltaic, dye.

\section{Introduction}

Due to the environmental problems such as global warming, depletion of fossil fuels, and the growth of the energy request, efforts to develop the environmental friendly renewable energy technologies are an urgent duty for human life [1]. Among all of the renewable energy technologies, solar cells are important photovoltaic devices for using the solar energy.

The dye-sensitized solar cell (DSSC) is a new type of the solar cells with efficient performance for the direct conversion of light into electrical power [2], which has been introduced by Grätzel and co-workers [3] and are the proper alternative for the p-n junction photovoltaic devices [4]. It has attracted considerable interest due to their low-cost [5], flexibility [6] and environmentally-friendly properties [7] and facile fabrication process [8]. A general DSCC consists of the different components stacked in serial, including transparent conducting glass substrate, transparent conducting layer, $\mathrm{TiO}_{2}$ nanoparticles, dyes, electrolyte, and the counter electrode [9]. The working principle of a DSSC is based on the electron excitation from the ground state to the higher-energy excited states of the sensitizer [10]. It is arisen through the photon absorption and followed by the injection of the excited electron from the photo-excited sensitizer to the conduction band (CB) of the semiconductor [11]. $\mathrm{TiO}_{2}$ transports the injected electrons into the conductive contact [12]. On the other hand, electrolyte reduces the oxidized dyes [13], and transports the holes to the counter electrode [14].

To date, developments in the cell efficiencies have been pertained to three main components of the DSSCs: dye, redox shuttle and the semiconductor electrode [15]. Since electric charge is generated through the light harvesting by a sensitizer, finding a reasonable 
relationship between the electronic structure of the sensitizers and the performance of the solar cells is important [16].

Porphyrin derivatives are considerable as the sensitizers in DSSCs. They show tunable visible absorption properties possessing a conjugated system of pyroles. Also, there is a possibility of the metal ion insertion at the center of these systems, yielding the organometallic complexes [17]. Moreover, other properties such as their proper redox potentials for sensitization of the large band-gap semiconductors (e.g. $\mathrm{TiO}_{2}$ ), low cost, relatively simple synthesis procedure [18], a high molar absorption coefficient, excellent chemical and thermal stability make them ideal sensitizers [19].

Some processes such as an efficient injection of electrons from the dye into a semiconductor, the regeneration of the oxidized dye by the electrolyte [20], losses resulting from charge transports and recombination are important in determining the efficiency of the DSSCs [21]. In an efficient DSSC, the lowest unoccupied molecular orbital (LUMO) energy level of a sensitizer should be higher than the CB edge of the semiconductor and it's the highest occupied molecular orbital (HOMO) energy level should be lower than the redox potential level of the electrolyte. Moreover, the absorption spectrum of a dye should overlap efficiently with the solar spectrum [22]. In addition to these factors, the performance of a solar cell can be developed through the proper modification of the sensitizer electronic structure and solvent effects [23].

The porphyrin system shows a wide and intense optical absorption band which arises from the appropriate HOMO and LUMO energy levels. This band consists of strong absorption in the region of 350 - $500 \mathrm{~nm}$ (Soret or B-band) and 550 - $700 \mathrm{~nm}$ (Q-band) [24]. In the past few years, studies have shown an abrupt improvement in the efficiency of DSSCs [25]. Most of these studies are on the basis of changes in the molecular geometries of the 
sensitizers and their effect on the solar cell efficiency. Therefore, such studies are helpful to interpret the optical properties and electron transfer phenomena in the DSSCs and designing of the new efficient sensitizers.

Although, numerous experimental efforts have been done on the improvement in the energy conversion of the DSSCs, but in order to have a meaningful insight into the solar cell efficiency, a molecular approach is necessary for investigation of the photophysical and photochemical properties of the applied materials [26]. Also, a knowledge of the possible correlations between the quantum chemistry descriptors and solar cell efficiency enables us to predict the best price/efficiency ratio in the DSSCs [27].

Since, in our previous study, the performance of a series of the porphyrin-based sensitizers have been investigated as a function of the position of the anchoring and alkyl side groups [28], it is a great of interest to know, what occurs during the electron-transfer dynamic of the other porphyrin derivatives in the solvent media. Here, with this in mind and using the quantum chemistry approach, we theoretically investigate another type of porphyrins with different structures as the light-harvesting units within a carboxylic acid as an anchoring group in the gas and solution phases, for the first time. To better understand the electrontransfer dynamics in the porphyrin derivatives, we have analyzed the quantum reactivity parameters such as the electrophilicity index $(\omega)$, the electronic chemical potential $\left(\mu_{\mathrm{e}}\right)$, the chemical hardness $\left(\eta_{q}\right)$ and charge transfer. Since the transition metal complexes are often used as the photoactive compounds in the sunlight-based technologies, $\mathrm{Zn}$ (II) polyphyrin derivatives [29] have been investigated in this work.

\section{Theory and Computational Details}

To optimize the ground state structures, the density functional theory (DFT)/B3LYP/6-31G(d,p) level of the theory was used [30]. Furthermore, to consider the 
excited states and optical properties, the time-dependent DFT (TD-DFT) calculations [31] with the larger basis set of 6-311++G(d,p) [32] within the B3LYP/CAM-B3LYP functionals were applied [33].

In order to have an accurate representation of the excitation energies in the realistic environment, the solvent effects of methanol $\left(\mathrm{MeOH} ; \mathrm{CH}_{3}-\mathrm{OH}\right)$ and tert-butanol $(\mathrm{t}-\mathrm{BuOH}$; $\left.\mathrm{C}\left(\mathrm{CH}_{3}\right)_{3}-\mathrm{OH}\right)$ have been evaluated by the non-equilibrium version of the conductor-like polarizable continuum (CPCM) model [34]. Also, to describe the diffusion of electrons into the atomic and molecular orbitals, natural bond orbital (NBO) analysis, has been carried out [35]. Through this analysis, it is possible to have insight into the various stabilizing interactions in the ground state of the dye-sensitizers [36]. Based on the data obtained from the orbital analysis, it is possible to be described the photon-to-electric conversion efficiencies [37].

Within the conceptual framework of the DFT [38], $\mu_{e}, \eta_{q}$, and $\omega$, have been evaluated using the Koopman's theorem [39]. $\mu_{e}$ shows the escape tendency of an electron from an equilibrium state. $\eta_{q}$ and $\omega$ represent the resistance to the charge transfer (CT) and the stabilization energy of the saturated systems by electrons of the surroundings, respectively [40]. These parameters can represent the role of the structure and medium on the performance of a sensitizer. For example, the chemical hardness or softness arises from HOMO-LUMO energy difference, which is affected by the geometrical parameters of the chemicals and their interactions with the solvent. Also, $\omega$ is an intrinsic property of atoms and molecules which measures the stabilization in energy when the system gains an additional electronic charge from the media. Gaussian 09 program [41] has been used for all calculations.

\section{Results and Discussion}

\subsection{Electronic structures and photovoltaic parameters}


Fig. 1 shows the optimized structures of the porphyrin-based dyes named as BP; 5(biphenyl-4-carboxylic acid)- 10,15,20-tris(2,4,6-trimethyphenyl)porphyrinatozinc (II), CNBP; 5-(biphenyl-4-carboxylic acid)-10,20-di(2,4,6-trimethyphenyl)-15phenylnitrileporphyrinatozinc $\quad$ (II), CNMP; 5-(4-carboxylphenyl)-10,20-di(2,4,6trimethyphenyl)-15-phenylnitrileporphyrinatozinc (II) and MP; 5-(4-carboxyphenyl)10,15,20-tris(2,4,6-trimethyphenyl)porphyrinatozinc (II) in the gas phase. We have reported the corrected energies by the thermal and zero point vibrational energies in Table 1 for all of the studied dyes in the gas and solvent phases.

Fig. 1

Table 1

Comparison between the total energies of the dyes in the gas phase and solvents shows the solvent media can stabilize the dye structures through the intermolecular interactions of the dye and the solvent.

Sunlight-to-electricity conversion efficiency, $\eta$ in equation 1 , of the solar cell is described by the open-circuit photovoltage $\left(V_{O C}\right)$, short-circuit current density $\left(J_{S C}\right)$, and fill factor $(F F)$, as compared to the incident solar power $\left(P_{i n c}\right)[42]$ :

$$
\eta=\frac{J_{s c} V_{O C} F F}{P_{\text {inc }}}
$$

Where, $\mathrm{J}_{\mathrm{SC}}$ in DSSCs is determined by the equation 2 [43]:

$$
J_{S C}=\int_{\lambda_{1}}^{\lambda_{2}} q \cdot \operatorname{IPCE}(\lambda) \cdot \phi(\lambda) d \lambda
$$

Where, $\phi(\lambda)$ is the incident photon flux at a given wavelength. Usually, this integrated current is used to cross-check with the J-V experimental data. The incident photon to current conversion efficiency (IPCE) reflects a series of the basic processes within a DSCC; the 
amount of absorbed photons $(L H E)$, injection efficiencies $\left(\phi_{i n j}\right)$ and collecting electrons $\left(\eta_{c o l l}\right)$, (Eq. 3) [44].

$$
\text { IPCE }=\operatorname{LHE}(\lambda) . \Phi_{\text {inject }} \cdot \eta_{\text {collect }}
$$

Where, $\operatorname{LHE}(\lambda)$ is the light harvesting efficiency at a given wavelength, $\Phi_{\text {inject }}$ shows the electron injection efficiency, and $\eta_{\text {coll }}$ defines the charge collection efficiency. In the systems which are only different in sensitizers, $\eta_{\text {collect }}$ can be wisely considered to be constant.

Internal quantum efficiency is known as the absorbed photon-to-current conversion efficiency $(A P C E)$ and is related to a part of the incident light which absorbed and caused the generation of the photoelectrons in a device (Eq. 4). According to equation 4, if APCE is low, it indicates the problem either in a poor electron injection, or difficulties in the charge delivery to the current collectors.

$$
\text { APCE }=\Phi_{\text {inject }} \cdot \eta_{\text {collect }}
$$

$\Phi_{\text {inject }}$ is related to the driving force, the free energy change of electron injection $\left(\Delta G_{\text {inject }}\right)$ of the electron injection from the excited states of dyes to the semiconductor substrate, which can be calculated by equations 5,6 [45]:

$$
\Delta G_{\text {inject }}=E_{O X\left(d y e^{*}\right)}-E_{C B, T i O 2}
$$

Where, $E_{C B(T i O 2)}$ is the conduction band energy of the $\mathrm{TiO}_{2}$ and $E_{O X\left(d y e^{*}\right)}$ is the excited state oxidation potential of the dye, which Rehm and Weller equation can determine its value (Eq. 6) [46].

$$
E_{O X\left(d y e^{*}\right)}=E_{O X(d y e)}-E_{0-0}+\omega_{r}
$$


Where, $E_{O X(d y e)}$ is the oxidation potential of the dye molecule in the ground state while $E_{0-0}$ is the vertical excitation energy and $\omega_{r}$ is a columbic stabilization term which is negligible [47]. Therefore $E_{O X\left(d y e^{*}\right)}$ is approximated by $E_{O X(d y e)}-E_{0-0}$.

The electron injection from the excited dye to the $\mathrm{CB}$ of the semiconductor and the dye regeneration processes can be defined as the $\mathrm{CT}$ reaction. The oxidation potential of the dyes must be more positive than that of the electrolyte to make fast and efficient regeneration of the cation radical and avoid the charge recombination between the oxidized dye sensitizers and semiconductor.

According to the Marcus theory of the electron transfer [48], free energy change of the reaction affects the $\mathrm{CT}$ rate constants. Also, as the electron injection rate is influenced by the $\Delta G_{\text {inject }}$, therefore $\Delta G_{\text {inject }}$ perturbs the $J_{s c}$ in the DSSCs which can be considered as the driving force for electron injection [49]. Also, the free energy change of regeneration $\left(\Delta G_{\text {regen (dye) }}\right)$ which is calculated by equation 7 , can affect the rate of the redox reaction between the oxidized dye and the electrolyte [50]:

$$
\Delta G_{\text {regen } \cdot(\text { dye })}=E_{\text {OX(dye) }}-E_{\text {redox(electrolyte })}
$$

Where, $E_{\text {redox(electrolyte) }}$ is the redox potential of the electrolyte which is commonly estimated as $4.85 \mathrm{eV}$ in $\left(\mathrm{I}^{-} / \mathrm{I}_{3}^{-}\right)$system [51]. We have computed the $\Delta G_{\text {inject }}$, ground and excited state oxidation potentials, $E_{O X(d y e)}, E_{O X\left(d y e^{*}\right)}$, and $\Delta G_{r e g e n \cdot(d y e)}$, for the corresponding porphyrin derivatives in the different phases and reported in Table 2.

\section{Table 2}

There is a cathodic shift in $E_{O X\left(d y e^{*}\right)}$ from the vacuum to the solvent for the most of the dyes, therefore the oxidization process of the excited dyes is more appropriate in the solvent 
than the gas phase. The behavior of the $E_{O X\left(d y e^{*}\right)}$ of the dyes in three phases is accorded to; $\mathrm{BP}<\mathrm{MP}<\mathrm{CNBP}<\mathrm{CNMP}$.

When the dye is absorbed on the semiconductor surface, photo-induce CT occurs at the interface. Therefore, inserting a biphenyl group instead of phenyl between the porphyrin ring and anchoring group (carboxylic group; $\mathrm{COOH}$ ) affects the various processes involved in DSSCs such as the dye oxidization and CT processes. Also the resonance effect and electron density are increased around the molecule surface, therefore the HOMO level is enhanced which in turn facilitates the electron injection. Replacing of 4-cyanophenyl group by 2,4,6-trimethylphenyl and biphenyl by phenyl cause a decrease in the electron injection and increase in the oxidation potential of the dyes which make them the worse oxidizing species.

Since all $\Delta G_{\text {inject }}$ are negative, there is a spontaneous CT from the excited state of the dye to the $\mathrm{CB}$ of $\mathrm{TiO}_{2}$ in DSSCs. Comparison between the obtained $\Delta G_{\text {inject }}$ in the gas and solution phases indicates the electrostatic interaction of the medium affect the stabilization of the electron injection and oxidation potential.

Despite the success of the CAM-B3LYP method for describing the long-range CT states of the organic complexes [52], here, we show that it fails to describe the metal-toligand charge transfers of the metalloporphyin compounds and then to the $\mathrm{CB}$ of the semiconductor.

According to Table 2, all of the calculated $\Delta G_{\text {regen.(dye) }}$ show that the studied dyes, which lose electrons, can be restored by taking electrons from the electrolyte, effectively. Elongation of the $\pi$-conjugation by biphenyl spacer and replacing of 4-cyanophenyl group by 2,4,6-trimethylphenyl decrease the $\Delta G_{\text {regen } \cdot(d y e)}$ and suppress the electron recombination. 
Generally, solvent enhances the HOMO energy level of dyes and decreases the required energy for the dye regeneration through the redox couple of the iodide/triiodide. But there are some fluctuations about the BP in which the maximum value of $\Delta G_{\text {regen.(dye) }}$ appears in the gas phase.

The performance of a dye in response to the incident light is another key factor in the DSSCs efficiency. $L H E$ of the dyes, should be high to maximize the photocurrent response. The $L H E$ is determined by eq. 8 [53].

$$
L H E=1-10^{-f}
$$

Where, $f$ is the oscillator strength of the dye obtained from the TD-DFT calculations, directly. Therefore, according to the equation $2, f$ and $\Delta G_{\text {inject }}$ functions can well estimate the approximate value of the $J_{S C}$. According to the Table 3 , the solvents have increased the calculated $L H E$, and the electron injection driving force $\left(\Delta G_{\text {inject }}\right)$ of the dyes, which the second parameter can modify the $\Phi_{\text {inject }}$ of the solar cells.

\section{Table 3}

Solvents enhance the $L H E$ of the dyes through the increase in the oscillator strength $(f)$, i.e. the solvents maybe increase the probability of the electronic transitions between the corresponding energy levels, and therefore increase the $f$, which is related to the strength of the electronic transitions. According to the equations 2 and 3, with increasing the $L H E$ of the dyes and the values of electron injection driving force $\left(\Delta G_{\text {inject }}\right)$, related to $\Phi_{\text {inject }}$, in the solvent media, it is predicted the solvents may be also increase the $J_{S C}$ and IPCE of dyes from vacuum to the solvent phases. We theoretically estimated the values of the IPCE of the dyes in different environments through the $L H E$ and $\Delta G_{\text {inject }}$ assessed by DFT and TD-DFT 
calculations. Fig. 2 shows the estimated value of the IPCE of the dyes in vacuum and solvent phases.

Computed data demonstrate the dyes in the solvent phase have better electron injection and efficient charges delivery to the current collectors in DSSCs rather than the vacuum. The maximum value of the theoretical IPCE is $7.71 \%$ in $\mathrm{t}-\mathrm{BuOH}$ which is lower than the experimental value of $76 \%$ [29]. It is reasonable to predict that small values of these theoretical data limit the theoretical solar cell performances. Although this comparison shows that the obtained data are not in accordance with the experiments, but it is important to be mentioned that the solar cell efficiency depends strongly on the device fabrication conditions. This means that it is not reasonable to compare directly the theoretical efficiency parameters with the experimental one even it is hard to compare the reported data from different research groups [29].

The exciton binding energy $(E B E)$, an important parameter on the efficiency of the exitonic solar cells, assesses the charge separation [54]. The EBE can be defined as the difference between the electronic and optical band gap energies (Eq. 9) [55]. The electronic band gap and the first excitation energy are defined as the energy difference of the HOMOLUMO levels and the optical gap, respectively [56]. Using the eq. 9, we have calculated these parameters and reported in Table 4.

Fig. 2

$$
E B E=\left(E_{L U M O}-E_{H O M O}\right)-E_{0-0}
$$

\section{Table 4}

Considering Table 4 and Fig. 3, it is indicated that methanol and tert-butanol decrease the $E B E$ values of the dyes, which is favorable in the photo-to-current energy conversion via 
a more effective dissociation of the excitons (hole/electron pair). The obtained theoretical $E B E$ trend is as follows; $\mathrm{MeOH}<\mathrm{t}-\mathrm{BuOH}<\mathrm{Gas}$ phase.

Fig. 3

It is interesting that $E B E$ and $L H E$ parameters are inversely correlated, implying that a dye with lower $E B E$ has a more efficient $L H E$ (Fig. 4). This behavior is in agreement with the relationship between the $E B E$ and quantum yield.

Fig. 4

Fig. 5 shows changes in the HOMO-LUMO gap of the studied dyes in different media. The maximum energy gap has been obtained in vacuum showing the low reactivity of these dyes in the gas phase. This result enables us to have a prediction of the higher $\mathrm{J}_{\mathrm{SC}}$ in the solvent than the gas phase. Usually, there is an effective electron injection in solar cell if the energy gap between the LUMO of the dye and the $\mathrm{CB}$ of the $\mathrm{TiO}_{2}\left(e V_{O C}\right)$ is more than 0.2 $\mathrm{eV}$ [57] (Eq. 10). Calculated values of the $e V_{O C}$ of the dyes in different phases have been reported in Table 5 .

$$
e V_{O C}=E_{L U M O}-E_{C B, T i O 2}
$$

Fig. 5

\section{Table 5}

A schematic profile of the energy levels of the HOMO and LUMO of the dyes in different media, redox potential energy of the electrolyte and the $\mathrm{CB}$ edge of $\mathrm{TiO}_{2}$ has been presented in Fig. 6. According to this figure, LUMO energy levels lie over the $\mathrm{CB}$ of $\mathrm{TiO}_{2}$ in all phases and the corresponding gap is more than $0.2 \mathrm{eV}$. Therefore, the corresponding sensitizers have an effective electron injection into the $\mathrm{TiO}_{2}$ electrodes in their excited states. The HOMO levels of the dyes are lower than reduction potential energy of the iodide/triiodide $\left(\mathrm{I}^{-} / \mathrm{I}_{3}{ }^{-}\right)$ electrolyte, so the redox process between the oxidized dyes and electrolyte can be done 
effectively. It means that there is a sufficient tendency for the fast regeneration of the dye and avoiding the couple charge recombination of the oxidized dyes and the nanocrystalline $\mathrm{TiO}_{2}$ film where the photo-excited electrons are injected. Therefore, all dyes show a positive response to $\mathrm{CT}$ and regeneration, related to photo-oxidation process.

Fig. 6

\subsection{Electronic absorption spectra}

Electronic absorption spectra of the porphyrins consist of two distinct regions, the Soret and Q bands. The Soret or B-bands are in the range of 380-500 nm, which is depended on the meso-substituted porphyrin derivatives. The Q bands are in the range of 500-750-nm, with a set of weaker peaks, but still considerably intensive consisted of a weak transition from the ground to the first excited states.

Therefore the changes in the conjugated system, symmetry and geometry of the porphyrins, which can affect the corresponding UV-Vis spectrum [58]. Moreover, according to the results of the TD-DFT calculations, Fig. 7, the shape of the absorption spectra is also strongly dependent on the media. In order to have a microscopic insight into the electronic transitions, we have calculated wavelengths, oscillator strengths, transition energies of the singlet transitions of the absorption bands in different phases and presented in Table S1.

Fig. 7

According to Table S1 there are some bands broadening and red-shift from the gas phase to the solvent due to a smaller energy gap of the dyes in these media. Such red shifts are in the range of 1-11 $\mathrm{nm}$ and mainly arise from the stabilizing of the virtual orbitals in the solvent environment. The solvent stabilizes the charge-separated excited states through electrostatic interactions between the media and the dye. So it can be concluded the calculated transition energies are sensitive to the solvent effects, too. 
Generally, both of the media and substituents on the porphyrin ring affect the relative intensity of absorption spectra. The substitution of the biphenyl instead of phenyl on the one of the meso-positions of the porphyrin ring and 2,4,6-trimethylphenyl substitution instead of 4-cyanophenyl group on the opposite position to the $\mathrm{COOH}$ group, shift the absorption spectra toward a longer wavelength with higher molar absorption coefficient. This is due to an increase in the $\pi$-electrons of the conjugated system. On the other hand, the corresponding excitons produce charge-separation states which play a key role in the photo-to-current conversion processes. Here, the type of the media causes the considerable changes in the absorption band intensity while biphenyl substituent instead monophenyl on the porphyrin ring changes it, less.

The excited state oxidation potential of the dye fluctuates in different media. According to Table $\mathrm{S} 1, \mathrm{E}_{0-0}$ of the sensitizers is reduced from the gas phase to methanol and tert-butanol, which means that the excited states in these solvents are more stable than the gas phase and subsequently, the electrons inject from the dye to the $\mathrm{CB}$ of the semiconductor, properly. We can conclude that solvent affect the excitation energy and photo-induced electron transfer processes, distinctly.

\subsection{Quantum reactivity indices}

Since accessing in the subatomic information such as the changes in the frontier energy levels are not easily possible in the experimental studies and they play an important role in the performance of the sensitizers, we have investigated the quantum reactivity indices through these energy levels. Moreover, since there is not a comprehensive analysis of the quantum chemical properties and the photovoltaic parameters in the previous studies, this work provides a new insight into the molecular energy levels and possible correlations with the efficiencies of the solar cells. 
Considering the band gap effect of the dyes on the photovoltaic parameters in DSSCs, it is expected that the conceptual DFT reactivity indices represent a molecular viewpoint on the efficiency of the solar cells. Most interesting part of these calculations is the study of the probable correlation of the quantum reactivity indices (Table 6) and the solar cell efficiency.

Based on Table 6 , the $\omega$ values of the nitrylated dyes are more than the other dyes, because the $\mathrm{CN}$ group pulls the $\pi$ electrons from the porphyrin ring and reduces the $\Delta G_{\text {inject }}$ which are unfavorable for solar cell performance. While phenyl replacement by the biphenyl group decreases the electrophilicity of the dyes and enhances the electron injection from the dye to $\mathrm{TiO}_{2}$, due to an increment in the $\pi$-electron conjugation system.

\section{Table 6}

Fig. 8 demonstrates a nearly good linear correlation between the $\Delta G_{\text {inject }}$ and the $\omega$ of the dyes in different media. The $\omega$ reduction is according to the inhibition of the electron capture in the dye which decreases the cell efficiency through the decrease in the $\left|\Delta G_{\text {inject }}\right|$. Therefore, a linear correlation of the oxidation energy between the dye and the $\omega$ is expected. This means that a more $\omega$ of the dye makes it more active in response to the incident photon.

Fig. 8

Change in the quantum reactivity indices alters the energy gap between the LUMO of the dye and the $\mathrm{CB}$ of the semiconductor, $e V_{O C}$. Figs. $\mathrm{S} 1$ and $\mathrm{S} 2$ show the correlation of the $e V_{O C}$ of the dye with $\eta_{\mathrm{q}}$ and $\omega$, respectively. Based on these figures, it is confirmed that an increase in the $e V_{O C}$, both of the $\eta_{\mathrm{q}}$ and $\omega$ of the dye decreases due to less tendency to the electron transfer.

\section{Conclusion}


In this research, the photovoltaic properties of four Zn-porphyrin derivatives and their quantum reactivity indices have been investigated. Here, using the DFT/B3LYP/6-311G(d,p) and TD-DFT/(B3LYP and CAM-B3LYP)/6-311++G(d,p) levels, we have respectively studied the electronic structures, properties, UV-Vis spectra and the CT processes for the BP, CNBP, CNMP and MP. These dye-based sensitizers have been studied in the gas and solution phases.

NBO analysis helps us to obtain the microscopic information about the electronic transitions. LUMO energy levels of these dyes are higher than the $\mathrm{CB}$ of the $\mathrm{TiO}_{2}$ which indicates that these dyes are thermodynamically favorable during the electron transfer process. Also, their HOMO energy levels lie under the reduction potential of the electrolyte $\left(\mathrm{I}^{-} / \mathrm{I}_{3}{ }^{-}\right)$corresponding to the ability of the proper dye regeneration. Based on these properties, it is expected that the corresponding dyes are good photosensitizers in the DSSC.

Inclusion of the solvent reduces the HOMO-LUMO gap and increases the oscillator strength and the intensity of the spectra within a red shift in the absorption spectra. Moreover, in the solvent phases, $E B E$ of the dyes is smaller and their light harvesting is higher than the gas phase, which shows a better efficiency of DSSCs in the solvent.

Apparently, elongation of the $\pi$-conjugated system through inserting a biphenyl spacer instead of the phenyl and 2,4,6-trimethylphenyl instead of the 4-cyanophenyl group increases the $\mathrm{CT}$ and suppress the electron recombination.

We presented that how the conceptual DFT reactivity indices affect the performance of the Zn-porphyrin sensitized solar cell. Based on these data, a linear correlation between the $\omega$ and $\Delta G_{\text {inject }}$ of the dyes has been obtained. 
Here, the theoretical results are in good agreement with the experimental values. We suggest that the chemical modifications of the dyes such as adding groups containing a more $\pi$-electron conjugated system and also applying the $\mathrm{MeOH}$ or t-BuOH solvents promotes the IPCE, $e V_{O C}$ and $L H E$ of the studied DSSCs.

Such analyses of the correlation between the electronic and molecular properties of the sensitizers with the expected efficiencies considering the solvent effects can improve the application aspects of the quantum chemistry, undoubtedly. Also, these findings provide a deeper understanding and a proper tool for modulating the solar cell efficiency.

\section{Acknowledgements}

Research Council of Ferdowsi University of Mashhad is gratefully acknowledged for the financial support of this work (Grant No. 3/31993). Also, we hereby acknowledge the Iran National Science Foundation: INSF, for supporting this project.

\section{References}

[1] Li B, Wang L, Kang B, Wang P, Qiu Y. Review of recent progress in solid-state dye-sensitized solar cells. Sol Energy Mater Sol Cells 2006;90:549-573.

[2] Grätzel M. Photoelectrochemical cells. Nature 2001;414:338-344.

[3] O’Regan B, Grätzel M. A low-cost, high-efficiency solar cell based on dye-sensitized colloidal $\mathrm{TiO}_{2}$ films. Nature 1991;353:737-740.

[4] Grätzel M. Dye-sensitized solid-state heterojunction solar cells. Mater Res Soc Bull 2005;30:23-27.

[5] Dao VD, Choi HS. Highly-efficient plasmon-enhanced dye-sensitized solar cells created by means of dry plasma reduction. Nanomaterials 2016;6:70-78.

[6] Ogawa J, Agrawal S, Koumura N, Mori Sh. Structural effects of the donor moiety on reduction kinetics of oxidized dye in dye-sensitized solar cells. J Phys Chem C 2016;120:3612-3618.

[7] Ambre RB, Mane SB, Hung CH. Zinc porphyrins possessing three p-carboxyphenyl groups: Effect of the donor strength of push-groups on the efficiency of dye sensitized solar cells. Energies 2016,;9:513-524.

[8] Kim G, Noh Y, Choi M, Kim K, Song O. Properties of working electrodes with IGZO layers in a dye sensitized solar cell. J Korean Ceram Soc 2016;53:110-115.

[9] Al-Bat'hi SA, Alaei I, Sopyan I. Natural photosensitizers for dye sensitized solar cells. IJRER 2013;3:138143. 
[10] Gebeyehu D, Brabec CJ, Sariciftci NS, Vangeneugden D, Kiebooms R, Vanderzande D, Kienberger F, Schindler H. Hybrid solar cells based on dye-sensitized nanoporous $\mathrm{TiO}_{2}$ electrodes and conjugated polymers as hole transport materials. Synth Met 2002;125:279-287.

[11] Liu SH, Fu H, Cheng YM, et al. Theoretical study of N749 dyes anchoring on the $\left(\mathrm{TiO}_{2}\right)_{28}$ surface in DSSCs and their electronic absorption properties. J Phys Chem C 2012;116:16338-16345.

[12] Docampo P, Guldin S, Leijtens T, Noel NK, Steiner U, Snaith HJ. Lessons learned: From dye-sensitized solar cells to all-solid-state hybrid devices. Adv Mater 2014;26:4013-4030.

[13] Wu J, Lan Z, Lin J, Huang M, Huang Y, Fan L, Luo G. Electrolytes in dye-sensitized solar cells. Chem Rev 2015;115:2136-2173.

[14] Yun S, Lund PD, Hinsch A. Stability assessment of alternative platinum free counter electrodes for dyesensitized solar cells. Energy Environ Sci 2015;8:3495-3514.

[15] Hamann TW, Jensen RA, Martinson ABF, Van Ryswyk H, Hupp JT. Advancing beyond current generation dye-sensitized solar cells. Energy Environ Sci 2008;1:66-78.

[16] Katono M, Bessho T, Wielopolski M, et al. Influence of the anchoring modes on the electronic and photovoltaic properties of D- $\pi$-A dyes. J Phys Chem C 2012;116:16876-16884.

[17] Lu J, Li H, Liu Sh, Chang YCh, Wu HP, Cheng Y, Diau EWG, Wang M. Novel porphyrin-preparation, characterization, and applications in solar energy conversion. Phys Chem Chem Phys 2016;18:6885-6892.

[18] Walter MG, Rudine AB, Wamser CC. Porphyrins and phthalocyanines in solar photovoltaic cells. J Porphyrins Phthalocyanines 2010;14:767-792.

[19] Tsai MCh, Wang ChL, Lin ChY, Tsai ChL, Yen HJ, Youb HCh, Liou GSh. A novel porphyrin-containing polyimide for memory devices. Polym Chem 2016;7:2780-2784.

[20] Zhao L, Wagner P, Barnsley GE, Clarke TM, Gordon KC, Mori Sh, Mozer AJ. Enhancement of dye regeneration kinetics in dichromophoric porphyrin-carbazole triphenylamine dyes influenced by more exposed radical cation orbitals. Chem Sci 2016;7:3506-3516.

[21] Chen Y, Li A, Huang ZhH, Wang LN, Kang F. Porphyrin-based nanostructures for photocatalytic applications. Nanomaterials 2016;6:51-75.

[22] Bagheri Novir S, Hashemianzadeh SM. Computational investigation of low band gap dyes based on 2styryl-5-phenylazo-pyrrole for dye-sensitized solar cells. Curr Appl Phys 2014;14:1401-1410.

[23] Zhang X, Gou F, Zhao D, Shi J, Gao H, Zhu Zh, Jing H. $\pi$-Spacer effect in dithiafulvenyl- $\pi$-phenothiazine dyes for dyesensitized solar cells. J Power Sources 2016;324:484-491.

[24] Guo M, He R, Dai Y, Shen W, Li M. Electron-deficient pyrimidine adopted in porphyrin sensitizers: A theoretical interpretation of $\pi$-spacers leading to highly efficient photo-to-electric conversion performances in dye-sensitized solar cells. J Phys Chem C 2012;116:9166-9179.

[25] Ma R, Guo P, Yang L, Guo L, Zeng Q, Liu G, Zhang XJ. A theoretical interpretation and screening of porphyrin sensitizer candidates with anticipated good photo-to-electric conversion performances for dyesensitized solar cells. J Mol Struct Thechem 2010;942:131-136.

[26] Pastore M, Mosconi E, De Angelis F, Grätzel M. A computational investigation of organic dyes for dyesensitized solar cells. J Phys Chem C 2010;114:7205-7212.

[27] Feng J, Xiao B. Effective masses and electronic and optical properties of nontoxic $\mathrm{MASnX}_{3}(\mathrm{X}=\mathrm{Cl}, \mathrm{Br}$, and I) perovskite structures as solar cell absorber: A theoretical study using HSE06. J Phys Chem C 2014;118:19655-19660.

[28] Arkan F, Izadyar M, Nakhaeipour A. A quantum chemistry study on the performance of porphyrin-based solar cell sensitisers; Zinc and anchor group position effects. Mol Phys 2015;113:3815-3825. 
[29] Ye S, Kathiravan A, Hayashi H, Tong Y, Infahsaeng Y, Chabera P, Pascher T, Yartsev AP, Isoda S, Imahori H, Sundström V. Role of adsorption structures of Zn-porphyrin on $\mathrm{TiO}_{2}$ in dye-sensitized solar cells studied by sum frequency generation vibrational spectroscopy and ultrafast spectroscopy. J Phys Chem C 2013;117:6066-6080.

[30] Godbout N, Salahub DR, Andzelm J, Wimmer E. Optimization of Gaussian-type basis sets for local spin density functional calculations. Part I. Boron through neon, optimization technique and validation. Can J Chem 1992;70:560-571.

[31] Stratmann RE, Scuseria GE, Frisch MJ. An efficient implementation of time-dependent density-functional theory for the calculation of excitation energies of large molecules. J Chem Phys 1998;109:8218-8224.

[32] Koch W, Holthausen MC. A chemist's guide to density functional theory. Germany: Wiley-VCH; 2001.

[33] Lee C, Yang W, Parr RG. Development of the Colle-Salvetti correlation energy formula into a functional of the electron density. Phys Rev B 1988;37:785-789.

[34] Cossi M, Barone V. Time-dependent density functional theory for molecules in liquid solutions. J Chem Phys 2001;115:4708-4717.

[35] Reed AE, Curtiss LA, Weinhold F. Intermolecular interactions from a natural bond orbital, donor-acceptor viewpoint. Chem Rev 1988;88:899-926.

[36] Xu J, Wang L, Liang G, Bai Z, Wang L, Xu W, Shen X. Density functional theory study on triphenylamine-based dye sensitizers containing different donor moieties. Bull Korean Chem Soc 2010;31(9):2531-2536.

[37] Yang L, Guo L, Chen Q, Sun H, Liu J, Zhang X, Pan X, Dai S. Theoretical design and screening of panchromatic phthalocyanine sensitizers derived from TT1 for dye-sensitized solar cells. J Mol Graph Model 2012;34:1-9.

[38] Parr RG, Yang W. Density functional theory of atoms and molecules. New York: Oxford University Press; 1989.

[39] Koopmans T, Over the allocation of wave functions and eigenvalues for the individual electrons one atom. Physica 1934;1:104-113.

[40] Islam N, Ghosh DC. On the electrophilic character of molecules through its relation with electronegativity and chemical hardness. Int J Mol Sci 2012;13:2160-2175.

[41] Frisch MJ, Trucks GW, Schlegel HB, Scuseria GE, Robb MA, Cheeseman JR, Montgomery JA, Vreven T, Kudin KN, Burant JC, et al. Gaussian 09, Revision A02, Gaussian Inc: Wallingford CT; 2009.

[42] Feng J, Jiao Y, Ma W, Nazeeruddin MdK, Grätzel M, Meng Sh. First principles design of dye molecules with ullazine donor for dye sensitized solar cells. J Phys Chem C 2013;117:3772-3778.

[43] Zhang J, Li HB, Sun SL, Geng Y, Wu Y, Su ZM. Density functional theory characterization and design of high-performance diarylamine-fluorene dyes with different $\pi$ spacers for dye-sensitized solar cells. J Mater Chem 2012;22:568-576.

[44] Ishida M, Park SW, Hwang D, Koo YB, Sessler JL, Kim DY, Kim D. Donor-substituted $\beta$-functionalized porphyrin dyes on hierarchically structured mesoporous $\mathrm{TiO}_{2}$ spheres. highly efficient dye-sensitized solar cells. J Phys Chem C 2011;115:19343-19354.

[45] Katoh R, Furube A, Yoshihara T, Hara K, Fujihashi G, Takano S, Murata S, Arakawa H, Tachiya M. Efficiencies of electron injection from excited $\mathrm{N} 3$ dye into nanocrystalline semiconductor $\left(\mathrm{ZrO}_{2}, \mathrm{TiO}_{2}, \mathrm{ZnO}\right.$, $\mathrm{Nb}_{2} \mathrm{O}_{5}, \mathrm{SnO}_{2}, \mathrm{In}_{2} \mathrm{O}_{3}$ ) films. J Phys Chem B 2004;108:4818-4822.

[46] Rehm D, Weller A. Kinetics of fluorescence quenching by electron and H-atom transfer. Isr J Chem 1970;8:259-271.

[47] Goodman JL,Peters KS. Effect of solvent and salts on ion pair energies in the photoreduction of benzophenone by DABCO. J Am Chem Soc 1986;108:1700-1701. 
[48] Marcus RA, Electron transfer reactions in chemistry. Theory and experiment. Rev Mod Phys 1993;65:599610 .

[49] Fan W, Tan D, Deng WQ. Acene-modified triphenylamine dyes for dye-sensitized solar cells: A computational study. Chem Phys Chem 2012;13:2051-2060.

[50] Zhang CR, Liu L, Zhe JW, Jin NZh, Ma Y, Yuan LH, Zhang ML, Wu YZh, Liu ZJ, Chen HSh. The role of the conjugate bridge in electronic structures and related properties of tetrahydroquinoline for dye sensitized solar cells. Int J Mol Sci 2013;14:5461-5481.

[51] Boschloo G, Hagfeldt A. Characteristics of the iodide/triiodide redox mediator in dye-sensitized solar cells. Acc Chem Res 2009;42:1819-1826.

[52] Martsinovich N, Troisi A. Theoretical studies of dye-sensitised solar cells: from electronic structure to elementary processes. Energy Environ Sci 2011;4:4473-4495.

[53] Qin C, Clark AE. DFT characterization of the optical and redox properties of natural pigments relevant to dye-sensitized solar cells. Chem Phys Lett 2007;438:26-30.

[54] Kim BG, Zhen CG, Jeong EJ, Kieffer J, Kim Organic dye design tools for efficient photocurrent generation in dye-sensitized solar cells: exciton binding energy and electron acceptors. J. Adv Funct Mater 2012;22:16061612.

[55] Gregg BA, Excitonic solar cell. J Phys Chem B 2003;107:4688-4698.

[56] Scholes GD, Rumbles G. Excitons in nanoscale systems. Nat Mater 2006;5:683-696.

[57] Xu J, Zhu L, Wang L, Liu L, Bai Z, Wang L, Xu W. The effect of anchoring group number on molecular structures and absorption spectra of triphenylamine sensitizers: a computational study. J Mol Model 2012;18:1767-1777.

[58] Costa LD, Costa JIT, Tomé AC. Porphyrin macrocycle modification: Pyrrole ring-contracted or expanded porphyrinoids. Molecules 2016;21:320-327. 


\section{Caption for the Figures:}

Fig. 1 Optimized structures of the studied porphyrin derivatives in the gas phase at the B3LYP/6-31G(d,p) level.

Fig. 2 Theoretical values of the IPCE for all of the dyes in different phases.

Fig. 3 The $E B E$ of the dyes in different media at the TD-DFT/B3LYP/6-31++G(d,p) level.

Fig. 4 Inverse correlation between the $L H E$ and $E B E$ of the dyes in three phases at the TDDFT/B.3LYP/6-31++G(d,p) level.

Fig. 5 HOMO-LUMO gap of the dyes in different phases at the TD-DFT/B.3LYP/6$31++\mathrm{G}(\mathrm{d}, \mathrm{p})$ level.

Fig. 6 Schematic energy diagram of the $\mathrm{Zn}$-porpyrin based dyes, $\mathrm{TiO}_{2}$ and electrolyte $\left(\mathrm{I}^{-} / \mathrm{I}_{3}{ }^{-}\right)$.

Fig. 7 Simulated absorption spectra of the dyes calculated at TDDFT-B3LYP/6-311++G(d,p) and TDDFT B3LYP/6-311++G(d,p) level of the theory.

Fig. 8 Linear correlation of the $\omega$ and $\Delta G_{\text {inject }}$. 

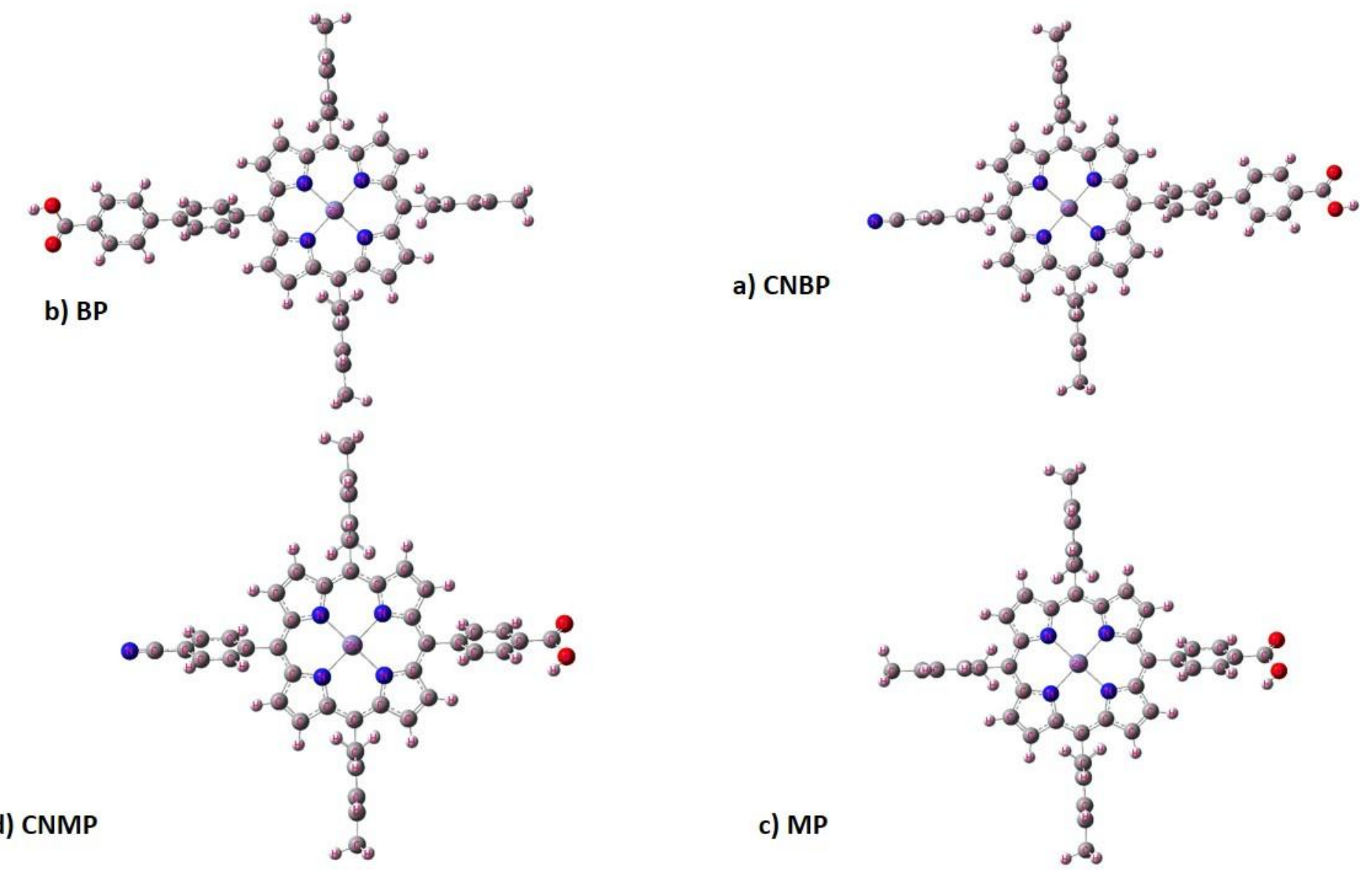

Fig. 1 


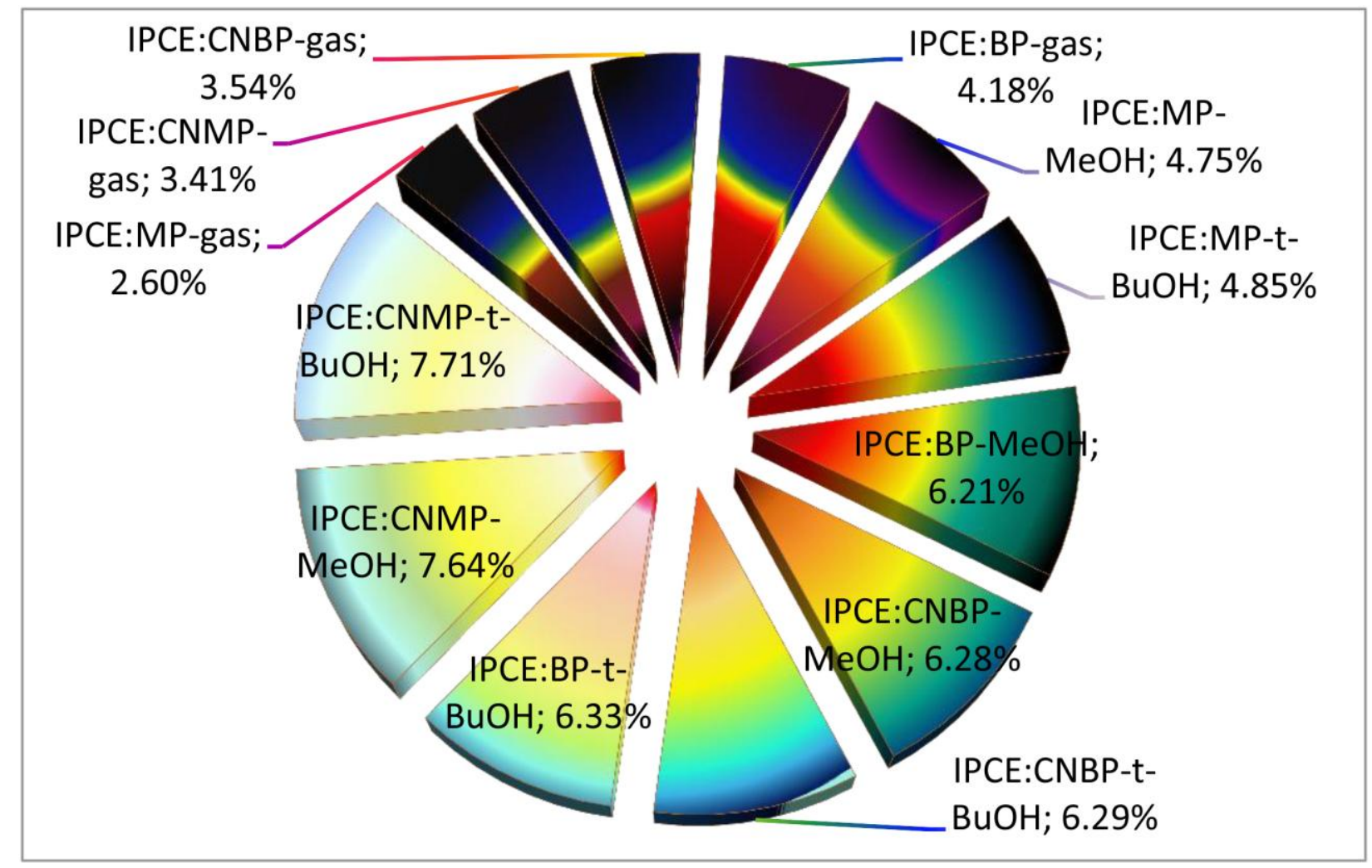

Fig. 2

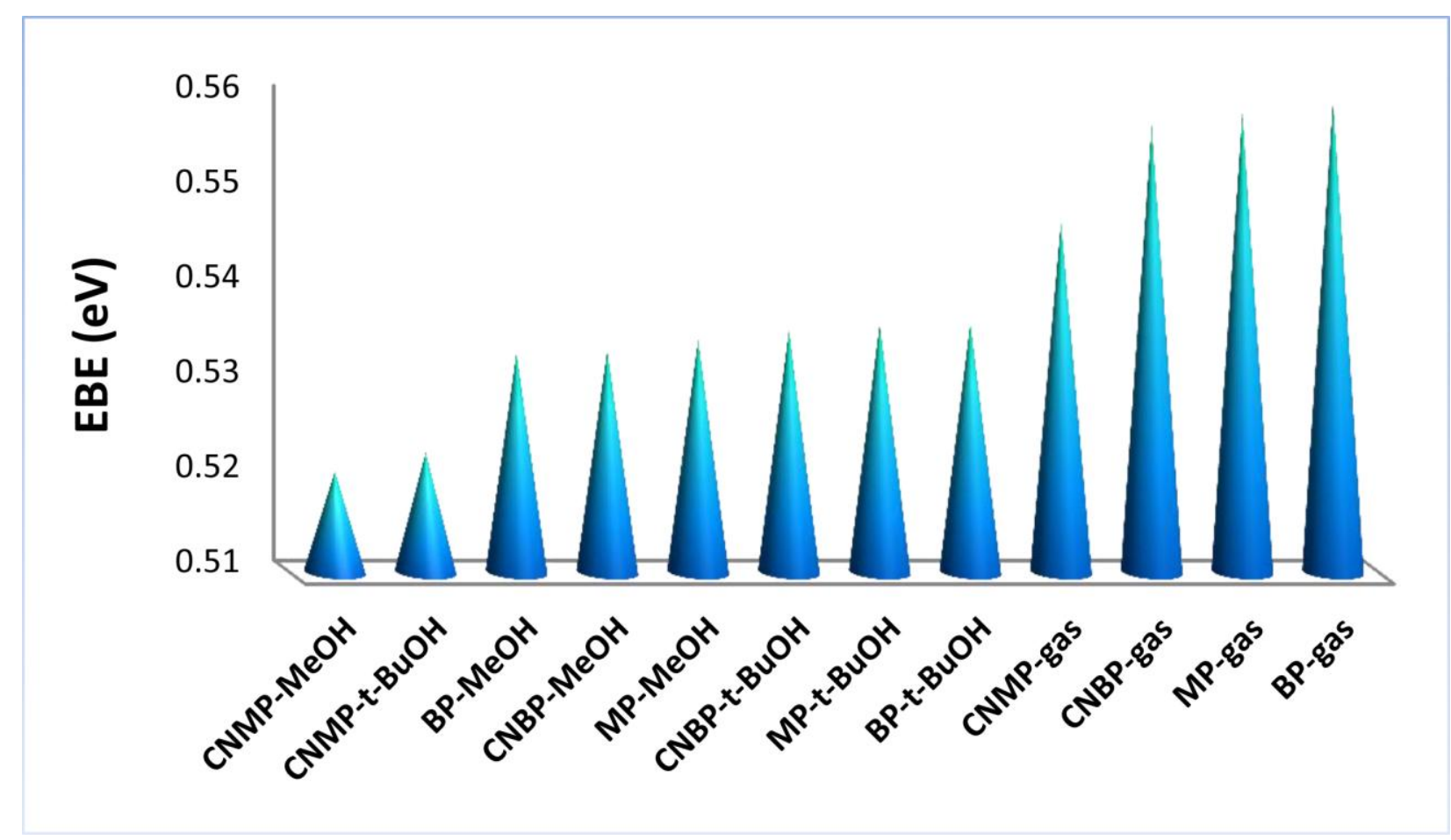

Fig. 3 


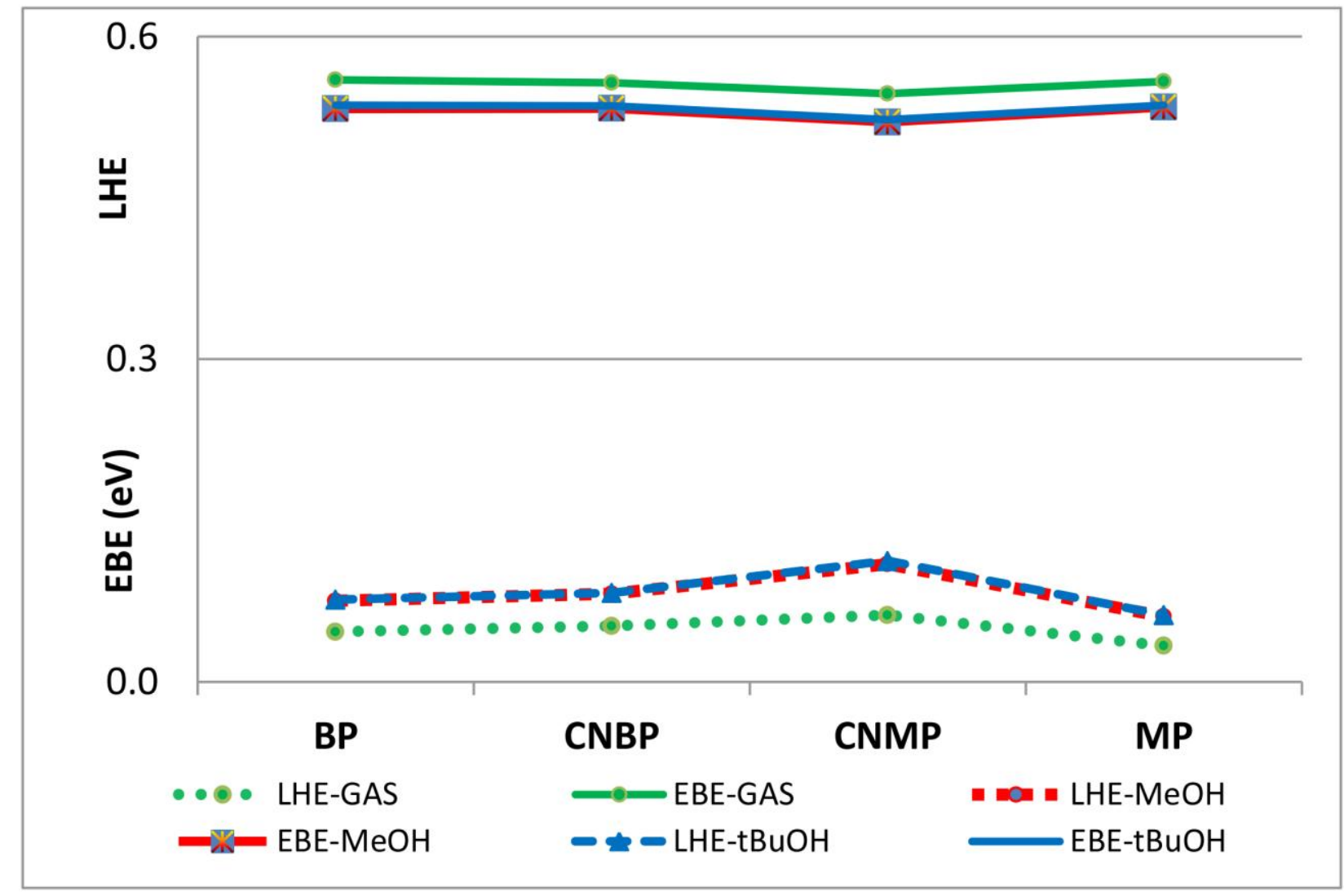

Fig. 4

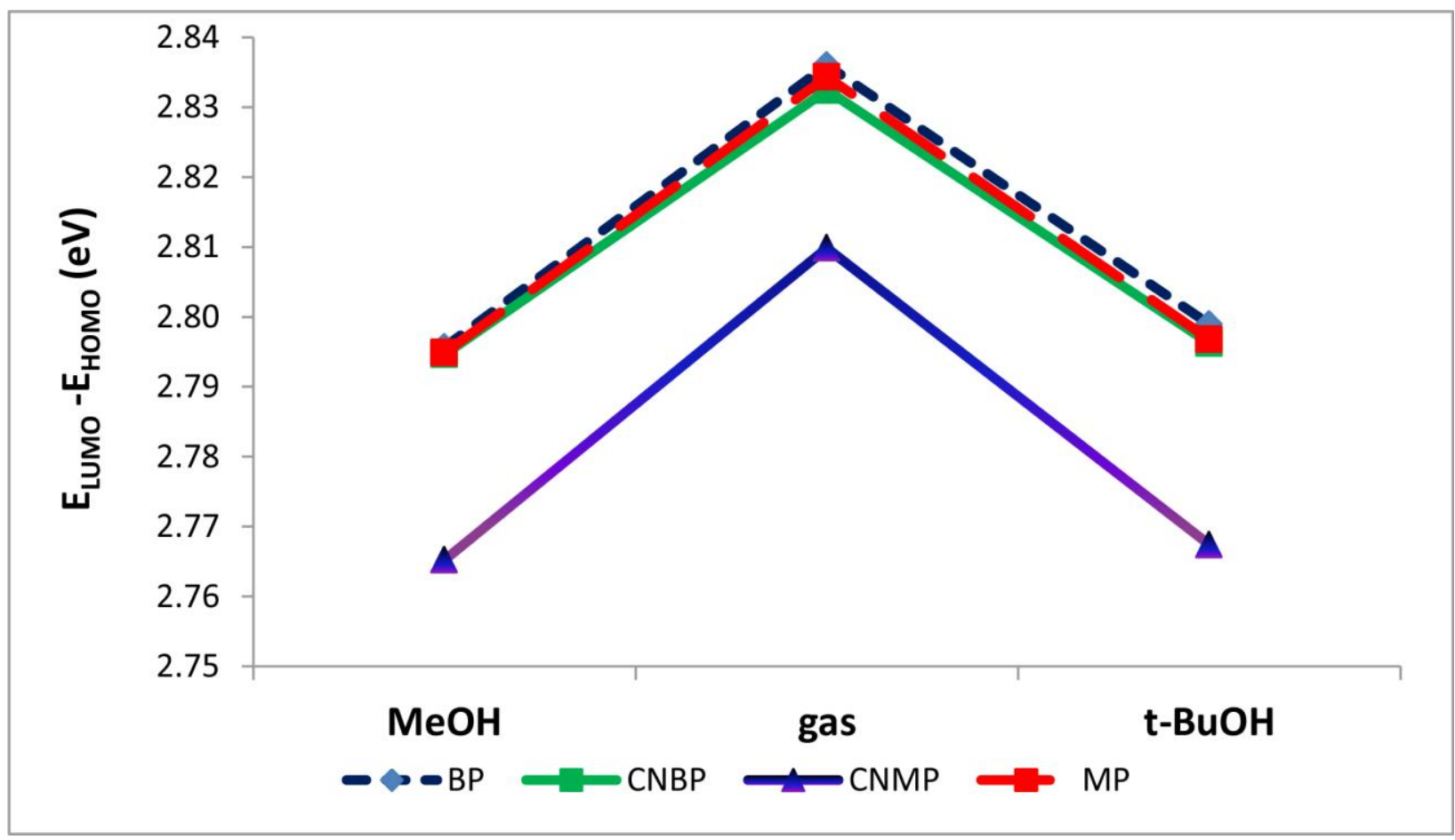

Fig. 5 


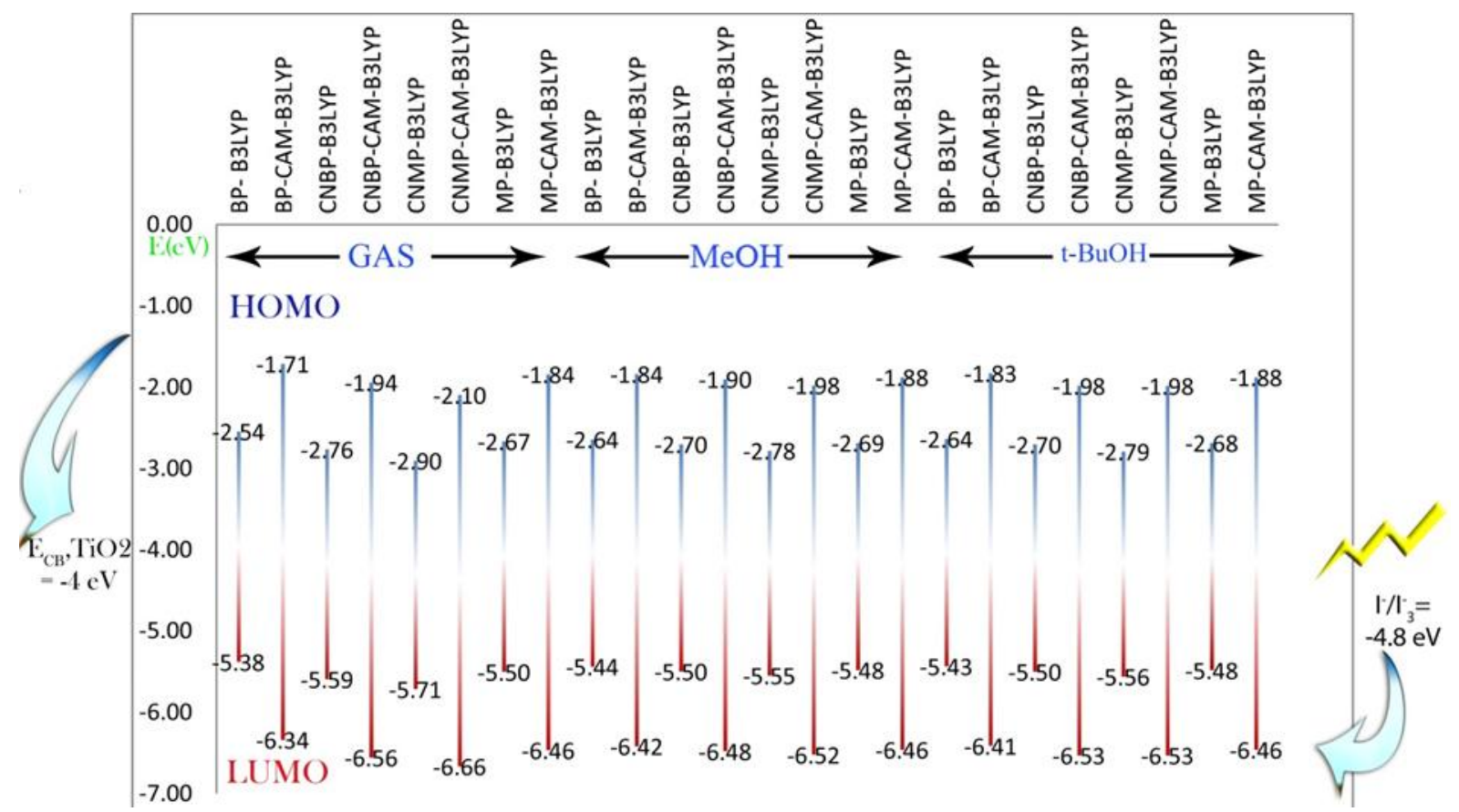

Fig. 6

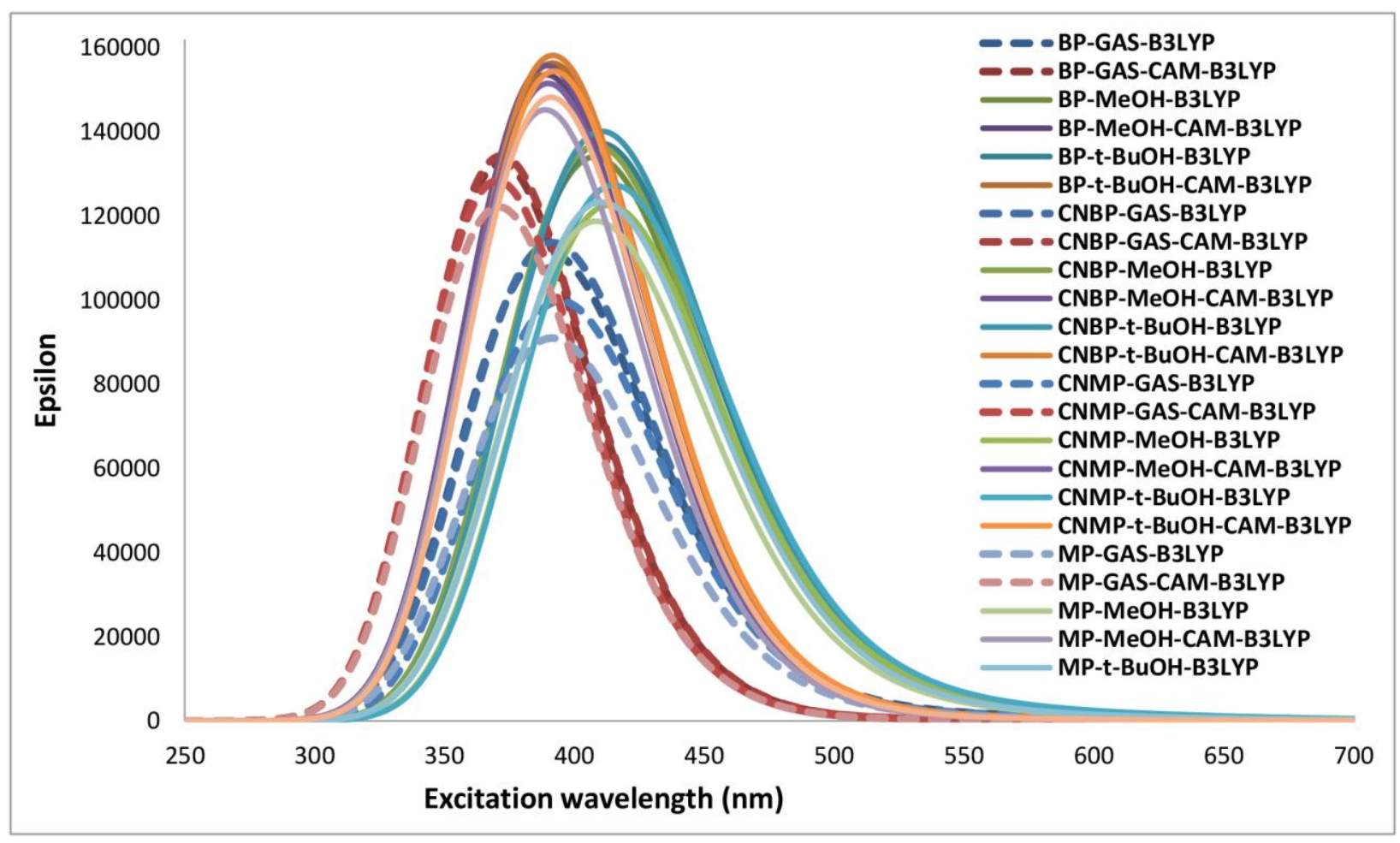

Fig. 7 


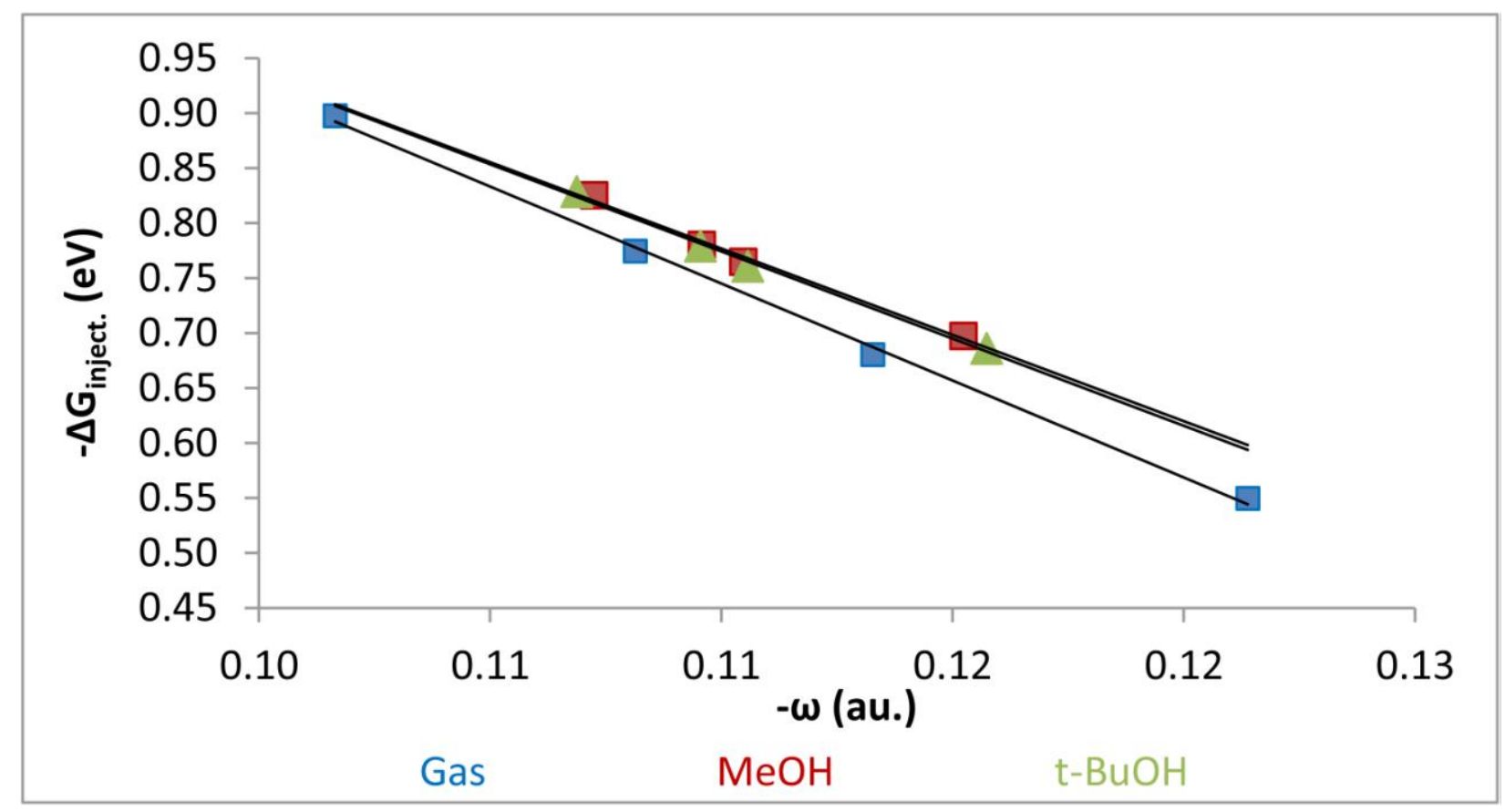

Fig. 8

Table 1 Calculated energies of the studied photosensitizers (-au.) at the B3LYP/6-31G(d,p) level of the theory

\begin{tabular}{lcccc}
\hline Phase & BP & CNBP & CNMP & MP \\
\hline Gas & 4465.352 & 4518.274 & 4208.558 & 4234.276 \\
MeOH & 4465.374 & 4518.301 & 4208.588 & 4234.301 \\
t-BuOH & 4465.373 & 4518.301 & 4208.586 & 4234.300 \\
\hline
\end{tabular}


Table 2 Estimated $E_{O X(d y e)}, E_{O X\left(d y e^{*}\right)}, \Delta G_{\text {inject }}$ and $\Delta G_{\text {regen } \cdot(d y e)}$ of the dyes in different phases (in $\mathrm{eV}$ )

\begin{tabular}{|c|c|c|c|c|c|c|c|c|c|}
\hline & & $\boldsymbol{E}_{\boldsymbol{O X}}$ & $\boldsymbol{E}_{\boldsymbol{O X}}$ & $\Delta \boldsymbol{G}_{\text {inject. }}$ & $\Delta G_{\text {regen }} \cdot($ dye $)$ & $E_{O X}$ & $\boldsymbol{E}_{\boldsymbol{O X}}$ & $\Delta \boldsymbol{G}_{\text {inject. }}$ & $\Delta G_{\text {regen } \cdot(\text { dye })}$ \\
\hline Compound & & & & B3LYP & & \multicolumn{4}{|c|}{ CAM-B3LYP } \\
\hline \multicolumn{10}{|l|}{ BP } \\
\hline & Gas & 5.379 & 3.103 & -0.897 & 0.529 & 6.338 & 4.104 & 0.104 & 1.488 \\
\hline & $\mathrm{MeOH}$ & 5.437 & 3.175 & -0.825 & 0.587 & 6.417 & 4.198 & 0.198 & 1.567 \\
\hline & $\mathrm{t}-\mathrm{BuOH}$ & 5.434 & 3.172 & -0.828 & 0.584 & 6.413 & 4.193 & 0.193 & 1.563 \\
\hline \multicolumn{10}{|l|}{ CNBP } \\
\hline & Gas & 5.595 & 3.320 & -0.680 & 0.745 & 6.557 & 4.324 & 0.324 & 1.707 \\
\hline & $\mathrm{MeOH}$ & 5.496 & 3.235 & -0.765 & 0.646 & 6.478 & 4.259 & 0.259 & 1.628 \\
\hline & $\mathrm{t}-\mathrm{BuOH}$ & 5.500 & 3.239 & -0.761 & 0.650 & 6.531 & 4.313 & 0.313 & 1.681 \\
\hline \multicolumn{10}{|l|}{ CNMP } \\
\hline & Gas & 5.713 & 3.450 & -0.550 & 0.863 & 6.665 & 4.431 & 0.431 & 1.815 \\
\hline & $\mathrm{MeOH}$ & 5.547 & 3.302 & -0.698 & 0.697 & 6.522 & 4.311 & 0.311 & 1.672 \\
\hline & $\mathrm{t}-\mathrm{BuOH}$ & 5.559 & 3.314 & -0.686 & 0.709 & 6.531 & 4.321 & 0.321 & 1.681 \\
\hline \multicolumn{10}{|l|}{ MP } \\
\hline & Gas & 5.501 & 3.225 & -0.775 & 0.651 & 6.465 & 4.231 & 0.231 & 1.615 \\
\hline & $\mathrm{MeOH}$ & 5.480 & 3.220 & -0.780 & 0.630 & 6.461 & 4.242 & 0.242 & 1.611 \\
\hline & $\mathrm{t}-\mathrm{BuOH}$ & 5.482 & 3.221 & -0.779 & 0.632 & 6.461 & 4.242 & 0.242 & 1.611 \\
\hline
\end{tabular}

Table $3 L H E$ of the dyes calculated at the TDDFT/B3LYP/6-31++G(d,p) and TD-DFT/CAMB3LYP/6-311++G(d,p) levels

\begin{tabular}{lccc}
\hline Compound & & B3LYP & CAM-B3LYP \\
\hline BP & & & \\
& Gas & 0.047 & 0.017 \\
& $\mathrm{MeOH}$ & 0.075 & 0.025 \\
CNBP & $\mathrm{t}-\mathrm{BuOH}$ & 0.076 & 0.025 \\
& & & \\
& $\mathrm{Gas}$ & 0.052 & 0.021 \\
$\mathbf{C N M P}$ & $\mathrm{MeOH}$ & 0.082 & 0.030 \\
& $\mathrm{t}-\mathrm{BuOH}$ & 0.083 & 0.029 \\
& & & \\
MP & $\mathrm{Gas}$ & 0.062 & 0.022 \\
& $\mathrm{MeOH}$ & 0.110 & 0.041 \\
& $\mathrm{t}-\mathrm{BuOH}$ & 0.112 & 0.041 \\
& & & \\
& $\mathrm{Gas}$ & 0.034 & 0.010 \\
& $\mathrm{MeOH}$ & 0.061 & 0.020 \\
& $\mathrm{t}-\mathrm{BuOH}$ & 0.062 & 0.020 \\
\hline
\end{tabular}


Table 4 The HOMO-LUMO gap, $\mathrm{E}_{\text {g.optical }}$ and calculated $E B E(\mathrm{in} \mathrm{eV}$ ) of the dyes in different phases at the TD-DFT/B3LYP/6-31++G(d,p) and TD-DFT/CAM-B3LYP/6-311++G(d,p) levels

\begin{tabular}{|c|c|c|c|c|c|c|c|}
\hline & & $\mathbf{E}_{\text {LUMO }}-\mathbf{E}_{\text {HOMO }}$ & $E_{0-0}$ & EBE & $\mathbf{E}_{\text {LUMO }}-\mathbf{E}_{\text {HOMO }}$ & $\mathbf{E}_{0-0}$ & EBE \\
\hline Compound & & \multicolumn{3}{|c|}{ B3LYP } & \multicolumn{3}{|c|}{ CAM-B3LYP } \\
\hline \multicolumn{8}{|l|}{$\overline{\text { BP }}$} \\
\hline & Gas & 2.836 & 2.276 & 0.560 & 4.623 & 2.233 & 2.390 \\
\hline & $\mathrm{MeOH}$ & 2.796 & 2.263 & 0.533 & 4.580 & 2.220 & 2.360 \\
\hline & $\mathrm{t}-\mathrm{BuOH}$ & 2.799 & 2.263 & 0.536 & 4.583 & 2.219 & 2.364 \\
\hline \multicolumn{8}{|l|}{ CNBP } \\
\hline & Gas & 2.832 & 2.275 & 0.557 & 4.617 & 2.233 & 2.384 \\
\hline & $\mathrm{MeOH}$ & 2.795 & 2.261 & 0.533 & 4.578 & 2.219 & 2.359 \\
\hline & $\mathrm{t}-\mathrm{BuOH}$ & 2.796 & 2.261 & 0.535 & 4.549 & 2.218 & 2.331 \\
\hline \multicolumn{8}{|l|}{ CNMP } \\
\hline & Gas & 2.810 & 2.263 & 0.547 & 4.569 & 2.234 & 2.335 \\
\hline & $\mathrm{MeOH}$ & 2.765 & 2.245 & 0.521 & 4.544 & 2.210 & 2.333 \\
\hline & $\mathrm{t}-\mathrm{BuOH}$ & 2.767 & 2.245 & 0.523 & 4.549 & 2.210 & 2.338 \\
\hline \multicolumn{8}{|l|}{ MP } \\
\hline & Gas & 2.834 & 2.276 & 0.558 & 4.621 & 2.233 & 2.388 \\
\hline & $\mathrm{MeOH}$ & 2.795 & 2.260 & 0.534 & 4.581 & 2.219 & 2.363 \\
\hline & $\mathrm{t}-\mathrm{BuOH}$ & 2.797 & 2.261 & 0.536 & 4.583 & 2.219 & 2.364 \\
\hline
\end{tabular}

Table 5 Energy gap between the LUMO of dye and the $\mathrm{CB}$ of the $\mathrm{TiO}_{2}\left(e V_{O C}\right.$, in eV) for all of the dyes

\begin{tabular}{lccc}
\hline Compound & & B3LYP & CAM-B3LYP \\
\hline BP & & & \\
& $\mathrm{Gas}$ & 1.457 & 2.286 \\
& $\mathrm{MeOH}$ & 1.358 & 2.162 \\
$\mathbf{C N B P}$ & $\mathrm{t}-\mathrm{BuOH}$ & 1.365 & 2.170 \\
& & & \\
& $\mathrm{Gas}$ & 1.237 & 2.060 \\
& $\mathrm{MeOH}$ & 1.298 & 2.100 \\
$\mathbf{C N M P}$ & $\mathrm{t}-\mathrm{BuOH}$ & 1.296 & 2.018 \\
& & & \\
& $\mathrm{Gas}$ & 1.097 & 1.904 \\
& $\mathrm{MeOH}$ & 1.218 & 2.022 \\
$\mathbf{M P}$ & $\mathrm{t}-\mathrm{BuOH}$ & 1.209 & 2.018 \\
& & & \\
& $\mathrm{Gas}$ & 1.333 & 2.156 \\
& $\mathrm{MeOH}$ & 1.315 & 2.120 \\
& $\mathrm{t}-\mathrm{BuOH}$ & 1.315 & 2.122 \\
\hline
\end{tabular}


Table 6 DFT reactivity indices, $\eta_{q}, \mu_{e}$ and $\omega$ (au.)

\begin{tabular}{|c|c|c|c|c|c|c|c|}
\hline & & $-\eta_{q}$ & $-\mu_{\mathrm{e}}$ & $-\omega$ & $-\eta_{q}$ & $-\mu_{\mathrm{e}}$ & $-\omega$ \\
\hline Compound & & \multicolumn{3}{|c|}{ B3LYP } & \multicolumn{3}{|c|}{ CAM-B3LYP } \\
\hline \multicolumn{8}{|l|}{ BP } \\
\hline & Gas & 0.104 & 0.146 & 0.102 & 0.17 & 0.148 & 0.064 \\
\hline & $\mathrm{MeOH}$ & 0.103 & 0.148 & 0.107 & 0.168 & 0.152 & 0.068 \\
\hline & $\mathrm{t}-\mathrm{BuOH}$ & 0.103 & 0.148 & 0.107 & 0.168 & 0.151 & 0.068 \\
\hline \multicolumn{8}{|l|}{ CNBP } \\
\hline & Gas & 0.104 & 0.154 & 0.113 & 0.17 & 0.156 & 0.072 \\
\hline & $\mathrm{MeOH}$ & 0.103 & 0.151 & 0.11 & 0.168 & 0.154 & 0.07 \\
\hline & $\mathrm{t}-\mathrm{BuOH}$ & 0.103 & 0.151 & 0.111 & 0.167 & 0.156 & 0.073 \\
\hline \multicolumn{8}{|l|}{ CNMP } \\
\hline & Gas & 0.103 & 0.158 & 0.121 & 0.168 & 0.161 & 0.077 \\
\hline & $\mathrm{MeOH}$ & 0.102 & 0.153 & 0.115 & 0.167 & 0.156 & 0.073 \\
\hline & $\mathrm{t}-\mathrm{BuOH}$ & 0.102 & 0.153 & 0.116 & 0.167 & 0.156 & 0.073 \\
\hline \multicolumn{8}{|l|}{ MP } \\
\hline & Gas & 0.104 & 0.15 & 0.108 & 0.17 & 0.153 & 0.069 \\
\hline & $\mathrm{MeOH}$ & 0.103 & 0.15 & 0.11 & 0.168 & 0.153 & 0.07 \\
\hline & $\mathrm{t}-\mathrm{BuOH}$ & 0.103 & 0.15 & 0.11 & 0.168 & 0.153 & 0.07 \\
\hline
\end{tabular}

